\title{
Religiosidade no Brasil
}

Rodrigo Franklin de Sousa ${ }^{I}$

$\mathrm{O}_{\mathrm{t}}^{\mathrm{t}}$ TÓPICO da religiosidade no Brasil tem recebido atenção renovada com a participação cada vez maior de grupos religiosos, não poucas vezes de orientação fundamentalista, no cenário político e midiático brasileiro. A discussão é normalmente formatada em termos das questões quentes do momento e se mostra como um lugar de formação de estereótipos e visões superficiais, como a repetida afirmação do declínio do catolicismo laico no Brasil e do crescimento desenfreado de um evangelicalismo radical, proselitista e monolítico. A presente reedição de artigos originalmente publicados na Revista USP, em 2005 - e acrescida de algumas contribuições originais - é leitura fundamental para quem busca um entendimento mais nuançado do que é a religião e a religiosidade no Brasil. O livro editado por João Baptista Borges Pereira oferece um retrato do rico e intrincado mosaico que, na realidade, caracteriza a religiosidade brasileira. Os artigos da coletânea revelam um Brasil para além dos estereótipos consagrados, um quadro religioso onde figuram, dentre outros, grupos budistas no Rio Grande do Sul, muçulmanos no Rio de Janeiro, xamãs em São Paulo, espíritas messiânicos na Paraíba e judeus no Pará.

É bem verdade que o campo religioso brasileiro é dominado pela matriz do cristianismo, uma vez que notamos que catolicismo e protestantismo abarcam 90\% dos brasileiros afiliados a alguma religião em nosso país. A essa ampla maioria somam-se ainda outras religiões e movimentos que têm alcançado pene- tração e expressividade cada vez maiores. Entretanto, mesmo dentro do contexto dessas manifestações cristãs majoritárias encontramos marcas de diversidade e pluralidade que correspondem a contingências históricas e a conjunturas sociais e culturais das mais diversas. A religiosidade brasileira possui uma identidade plástica e metamorfa, que trai os números censitários. É possível detectar alguns fatores históricos e sociais comuns que afetam, ainda que com suas especificidades, os diferentes grupos religiosos brasileiros. Esses fatores aparecem reiteradamente em diversos textos da coletânea.

A vinculação entre o cristianismo e a população brasileira tem raízes históricas profundas. Trazido pelos portugueses, o catolicismo sempre esteve intimamente vinculado à cultura e identidade brasileiras e passou por um processo de expansão e consolidação a partir da segunda metade do século XIX, com a revitalização do catolicismo na Europa, que influenciou o crescimento de novas práticas religiosas e devoções no Brasil, que matizaram definitivamente o catolicismo brasileiro (Augustin Wernet, "Congregações femininas no Brasil e o reavivamento religioso em fins do século XIX”). É principalmente no final do século XX que se pode reconhecer um franco declínio do catolicismo no Brasil (Faustino Teixeira, "Faces do catolicismo brasileiro"), o que aponta para um "processo de reconfiguração do campo religioso nacional" (Renata de Castro Menezes, "Uma visita ao catolicismo brasileiro contemporâneo: a bênção de Santo Antônio num convento carioca”). Nesse processo, é preciso pro- 
blematizar a ideologia da identificação simples entre catolicismo e identidade brasileira, ou mesmo a própria conceituação do que seria uma identidade católica (Renata de Castro Menezes, "Uma visita ao catolicismo brasileiro contemporâneo: a bênção de Santo Antônio num convento carioca"). O catolicismo brasileiro é plural e diverso, amplo, sincrético, heterogêneo, plástico. As suas várias vertentes podem ser tidas como um verdadeiro mosaico de experiências e vivências de espiritualidade, que absorvem e moldam elementos próprios da tradição católica assim como de outras tradições (Faustino Teixeira, "Faces do catolicismo brasileiro").

Pluralidade e diversidade também caracterizam as diversas configurações que as igrejas protestantes e evangélicas assumem no país. Testemunhamos tanto o crescimento vertiginoso de igrejas que se inserem agressivamente na mídia quanto o lento e progressivo crescimento de grupos minoritários que se valem de métodos tradicionais de transmissão de sua fé (Paulo Barrera Rivera, "A reinvenção de uma tradição no protestantismo brasileiro: a Igreja Evangélica Brasileira entre a Bíblia e a palavra de Deus"), tanto a dinâmica da instalação de grupos originários de outros países quanto de novos movimentos surgidos no Brasil. O protestantismo brasileiro também tem uma história longa e complexa, relacionada, por um lado, à chegada de diferentes grupos de imigrantes e, por outro, à atividade de grupos missionários. A distinção consagrada entre protestantismo de imigração e protestantismo de missão norteia vários textos do volume. Em alguns casos a distinção pode ser aplicada de forma clara, como no exemplo do luteranismo, situado fir- memente na primeira categoria (Lauri Emílio Wirth, "Protestantismo brasileiro de rito luterano"). Em outros, como no do anglicanismo, existem peculiaridades que não permitem uma aplicação simples dos conceitos (Carlos Eduardo B. Calvani, "Anglicanismo no Brasil"). Há também os casos em que grupos, que em sua configuração original estavam relacionados a imigrantes, passam por uma descaracterização progressiva de sua marca étnica e passam a se propagar por meio da atividade missionária e proselitista - como no caso do protestantismo originalmente italianizado da Congregação Cristã do Brasil (João Baptista Borges Pereira, "Italianos no protestantismo brasileiro: a face esquecida pela história da imigração").

Para além da distinção, percebe-se ainda que permanece uma complexa dinâmica entre as raízes estrangeiras do protestantismo e as configurações específicas que suas vertentes assumem no Brasil. Nesse sentido se destaca a influência ainda marcante dos Estados Unidos sobre o protestantismo brasileiro e o fato de que a trajetória das igrejas protestantes tradicionais de origem americana acontece no conflito entre dependência e autonomia (Antônio Gouvêa Mendonça, "O protestantismo no Brasil e suas encruzilhadas"). Nota-se, também, que o caso particular do pentecostalismo brasileiro deve ser analisado a partir de suas origens norte-americanas em conjunção com suas especificidades no Brasil (Leonildo Silveira Campos, "As origens norte-americanas do pentecostalismo brasileiro: observações sobre uma relação ainda pouco avaliada").

O choque entre os elementos tradicionais trazidos do pentecostalismo americano com a realidade do campo religio- 
so brasileiro produz por vezes elementos sincréticos. É o caso de segmentos neopentecostais, em particular a Igreja Universal do Reino de Deus, promotores de uma cruzada ideológica contra os cultos e tradições religiosas afro-brasileiras que, embora destoe do discurso de sincretismo e tolerância prevalentes no Brasil, cria simultaneamente um espaço simbólico novo em que tradições afro-brasileiras são absorvidas, rebatizadas e transfiguradas em um contexto evangélico (Vagner Gonçalves da Silva, "Concepções religiosas afro-brasileiras e neopentecostais: uma análise simbólica”).

O conflito entre a manutenção dos valores identitários (sejam eles étnicos ou doutrinários) de cada grupo e as contingências da cultura em ele está inserido pode ser descrita em termos de um choque ou de uma negociação. E essa tensão entra em foco em diversos textos da coletânea, em particular os que tratam de religiões que, embora universais e majoritárias em outros contextos, no Brasil se caracterizam como minoritárias ou circunstancialmente étnicas (João Baptista Borges Pereira, "Italianos no protestantismo brasileiro: a face esquecida pela história da imigração"). Um exemplo particular é o da Igreja Ortodoxa, parte ainda do contexto amplo do cristianismo, onde se percebe a luta contra a imigração e a aculturação, tentativa de manter a rigidez doutrinária e uma matriz étnica clara (Murício Loiacono, "A Igreja Ortodoxa no Brasil").

No caso do judaísmo, apresenta-se uma clara distinção entre a orientação baláchica e ortodoxa de uma vertente predominante em São Paulo - que prima pela diferenciação e separação do grupo e a maioria dos judeus brasileiros, como no caso dos do Pará, que privilegiam a formação de identidades complexas, que valorizam mais prontamente elementos próprios das culturas locais em que estão inseridos (Marta F. Topel, "Judaísmo(s) brasileiro(s): uma incursão antropológica”).

As comunidades islâmicas também deparam com a negociação entre identidade étnica, confissão doutrinária e inserção na cultura brasileira, questões que afetam o crescimento e as relações de poder no interior do grupo. Uma interessante solução encontrada nesse caso é a da doutrina da taqiya, que propõe o ocultamento de práticas e crenças com vistas à acomodação à tradição local e o benefício e segurança internos da comunidade. Entretanto, a resistência brasileira ao islamismo tem levado a comunidade xiita em locais como o Rio de Janeiro a um desencanto com relação a esforços nesse sentido (Paulo Gabriel Hilu da Rocha Pinto, "Ritual, etnicidade e identidade religiosa nas comunidades muçulmanas no Brasil").

O budismo chegou ao Brasil no final da década de 1950, e seu crescimento tem sido baseado no processo lento de pequenos grupos, de maneira que os resultados de sua inserção no Brasil só poderão ser percebidos em longo prazo (Ricardo Mário Gonçalves, “As flores do Dharma desabrocham sob o cruzeiro do sul: aspectos dos vários 'budismos' no Brasil"). Mas, novas religiões japonesas de matriz budista também têm, em maior ou menor escala, atraído o interesse dos brasileiros (Geraldo José de Paiva, "Novas religiões japonesas e sua inserção no Brasil: discussões a partir da psicologia”). Um caso de destaque é o da Sokka Gakkai no Rio Grande do Sul, que na tentativa de "otimizar" a propagação de sua fé no Brasil, tenta operar em torno 


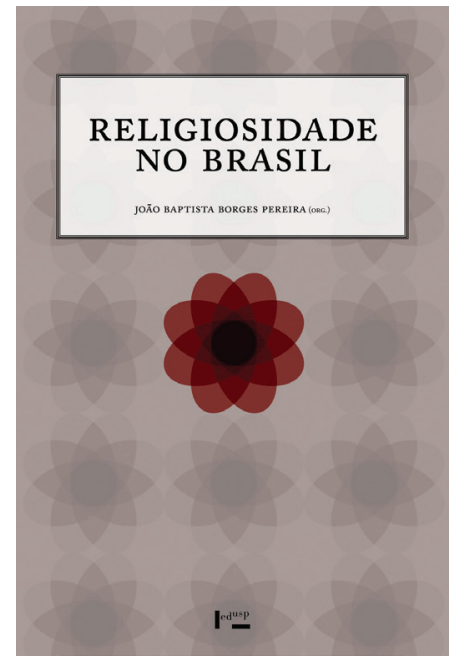

PEREIRA, J. B. B. Religiosidade no Brasil. São Paulo: Edusp, 2013.

de uma complexa dinâmica entre uma "face" pública simpática e acomodada à religiosidade brasileira e uma "face" interna que prima pelo reforço e não negociação de suas convicções e especificidades doutrinárias (Suzana Ramos Coutinho Bornholdt, "História, especificidades e inserção do budismo japonês da Sokka Gakkai no Sul do Brasil”).

Outro ponto de enfoque da coletânea diz respeito à inserção de crenças e práticas originariamente minoritárias na sociedade brasileira contemporânea e às formas como estas se moldam segundo tendências atuais. Por exemplo, as manifestações religiosas indígenas permanecem à margem da sociedade (Roque de Barros Laraia, "As religiões indígenas: o caso tupi-guarani”), embora sirvam, ainda que de maneira transversa, de inspiração para o chamado xamanismo urbano. Esse fenômeno agrega cosmologias indígenas a outros elementos constitutivos próprios da vida nas cidades, como forma de cultivo e expressão da religiosidade no contexto urbano contemporâneo (José Guilherme Cantor Magnani, "Xamãs na cidade"). São precisamente essas contingências da vida urbana que reconfiguram a relação entre religiosidade e economia, como no caso do espiritismo, que apresenta hoje segmentos que se desviam da proposta original voltada para a caridade e o desapego material, adotando noções de prosperidade e afluência como valores espirituais (Sandra Jacqueline Stoll, “O espiritismo na encruzilhada: mediunidade com fins lucrativos?").

Por vezes, a distopia entre ideário religioso e realidade concreta leva ao surgimento de movimentos radicais, milenaristas e messiânicos. Esses movimentos no Brasil surgiram em contextos predominantemente rurais, mas também em centros urbanos e comunidades indígenas e são apresentados como efetivados por atores intencionais, cujas ações se originam de uma cosmovisão particular e articulada (Renato da Silva Queiroz, "Mobilizações sociorreligiosas no Brasil: os surtos messiânico-milenaristas").

Os textos aqui reunidos variam desde aqueles que praticamente se limitam a uma descrição histórica ou circunstancial dos grupos abordados a releituras e propostas inovadoras. O conjunto permite uma visualização significativa dos matizes e processos de transformação constante da religiosidade no Brasil.

Rodrigo Franklin de Sousa é professor e coordenador do Programa de Pós-Graduação em Ciências da Religião da Universidade Presbiteriana Mackenzie.

@ - rodrigo.sousa@mackenzie.br

I Programa de Pós-Graduação em Ciências da Religião, Universidade Presbiteriana Mackenzie, São Paulo/SP, Brazil. 